\title{
Longitudinal changes in energy balance during pregnancy in South African women from the Tlokwe Municipal area
}

\section{Van Fourie Oort}

North-West University

Sarah J Moss ( $\sim$ Hanlie.moss@nwu.ac.za )

North-West University https://orcid.org/0000-0001-7938-1800

\section{Y Schutz}

Universite de Fribourg

\section{Research article}

Keywords: Energy intake, energy expenditure, energy balance, pregnancy, gestational weight gain

Posted Date: September 16th, 2019

DOI: https://doi.org/10.21203/rs.2.14442/v1

License: (c) (i) This work is licensed under a Creative Commons Attribution 4.0 International License.

Read Full License 


\section{Abstract}

Background Energy balance in the era of obesity, contributes to challenges in healthy weight maintenance. The study aims to determine the changes in energy intake and expenditure from the first to the third trimester of pregnancy in women from the Tlokwe Municipal area.

Methods We followed a longitudinal observational design to measure healthy pregnant women in the first (9-12 weeks), second (20-22 weeks) and third trimester (28-32 weeks). A valitdated, semi-quantitative food frequency questionnaire determined energy and macronutrient intakes. Energy expenditure (EE) was calculated from resting energy expenditure, as measured by indirect calorimetry (FitMate $\AA$ ), whereas activity energy expenditure was measured by combining heart rate and accelerometry (ActiHeart ${ }^{\circledR}$ ). Energy balance was calculated as the difference between energy expenditure and energy intake. A mixedmodel analysis was performed to determine significant differences between energy expenditure and intake during pregnancy.

Results Energy intake increased from the first ( $8841 \pm 3456 \mathrm{~kJ} /$ day) to the second trimester $(9134 \pm 3046$ $\mathrm{kJ} /$ day) and declined in the third trimester of pregnancy $(8171 \pm 3017 \mathrm{~kJ} /$ day). A negative energy balance was found during the first (-1374 $\pm 4548 \mathrm{~kJ} /$ day) and third trimesters $(-1331 \pm 3734 \mathrm{~kJ} /$ day), whereas a minor positive energy balance was observed in the second trimester ( $380 \pm 14212 \mathrm{~kJ} /$ day). Resting energy expenditure showed significant differences between the second and third, as well as the first and third trimesters. Changes in activity energy expenditure throughout pregnancy showed practical significance between the first and third trimesters.

Conclusions Energy intake and expenditure during pregnancy did not differ. The additional energy expenditure in the third trimester could be attributed to resting energy expenditure and a decrease in activity energy expenditure.

\section{Background}

Energy requirements during pregnancy is the energy intake from food that balances energy expenditure when the woman has a body composition and physical activity level consistent with good health $[1,2]$. The primary energy requirements of pregnancy provide a mean for adequate maternal weight gain to ensure growth of the fetus, placenta and associated maternal tissues [2,3]. Secondary energy requirements must allow for increased metabolic demands in addition to the energy necessary to maintain adequate maternal weight, body composition and physical activity throughout gestation, as well as providing energy stores to assist in lactation after delivery $[2,3]$. The additional energy required for pregnancy is estimated to be negligible during the first trimester, $1646 \mathrm{~kJ} /$ day in the second trimester and $2092 \mathrm{~kJ} /$ day in the third trimester [4]. By balancing energy intake with energy requirements for fetal growth and activity, energy balance will be reached where energy intake equals energy expenditure [2]. Energy balance during pregnancy can be achieved by various methods, including decreasing resting 
energy expenditure, mobilizing maternal fat stores, decreasing physical activity or increasing energy intake by increasing food intake $[3,5-8]$.

From a systematic review, it was found that energy intake during pregnancy in developing countries was $8971 \pm 1034 \mathrm{~kJ} /$ day, with the authors reporting a significantly higher energy intake in the third trimester compared to the first trimester [3]. However, in another study, it was found that healthy pregnancies can be achieved without significant increases in energy intake [9]. Women eat significantly more than is required to meet the energy requirements for a healthy pregnancy and therefore gain, on average, excess weight of more than $12 \mathrm{~kg}$ [10]. Excessive energy intake that contributes to excessive weight gain may increase the risk of developing pregnancy-induced hypertension [11] and increase the risk of caesarean birth, macrosomia [12], postpartum weight retention and gestational diabetes [13]. Therefore, the belief that increasing dietary energy intake will lead to an improved pregnancy outcome has no evidence-base $[3,14]$. Energy intake guidelines should, therefore, be individually adjusted to meet variations in basal metabolic rate, body composition before and during pregnancy, gestational weight gain and physical activity [15].

In conjunction with energy intake, maternal macronutrients (carbohydrates, lipids, and protein) influence fetal growth $(3,16,17)]$. The recommended percentage energy distributions of macronutrients during pregnancy are similar to those for healthy women, with the assumption that dietary energy intake is sufficient to maintain current body weight $[3,18]$. In addition, dietary intakes of pregnant women do not align with country-specific energy and macronutrient recommendations [3]. More specifically, total fat and saturated fat intake were generally higher than the recommended guidelines, while carbohydrates and poly-unsaturated fatty acid intake were lower than recommended [3].

During pregnancy, total energy expenditure increases due to the energy required for fetal growth, development of the placenta and various maternal tissues, as well as changes in maternal metabolism and the increase of energy expended during movement and activities of daily living resulting from weight gain $(1,2,9,19)$ ]. Total energy expenditure consists of basal metabolic rate, dietary-induced thermogenesis and energy expended during daily living activities and physical activity [2].

Basal metabolic rate-the primary component $(60 \%)$ of total energy expenditure-refers to the lowest level of energy expended at rest [20]. Basal metabolic rate tends to increase during pregnancy due to increased tissue mass and thus increased energy cost for maintenance [1, 9, 21]. Increases in both total energy expenditure and resting energy expenditure are more pronounced in the second and third trimesters [1, 21]. According to Butte \& King [1], on average, there is an increase of basal metabolic rate of $4.5 \%$ for the first, $10.8 \%$ for the second and $24.0 \%$ for the third trimesters, respectively.

Diet-induced thermogenesis is the energy required to digest and assimilate food and is considered to be small-about $5-10 \%$ of total energy expenditure [8]. However, little scope exists for energy savings concerning diet-induced thermogenesis during pregnancy, but there is considerable scope for adaptations in basal metabolism [22]. 
Any changes that occur in physical activity levels during pregnancy will have important implications for maternal energy requirements [23]. Energy expended during physical activity or activity energy expenditure refers to any energy expended above resting level, due to bodily movement [24]. Activity energy expenditure contributes to about $25-30 \%$ of total energy expenditure [25] in a developed world context. Energy expended during physical activity tends to decline during pregnancy due to decreases in habitual physical activity [1,26-28], which are likely due to minor discomforts such as leg cramps, swelling, fatigue, shortness of breath, difficulties in movement due to weight gain and perceptions that physical activity might pose risks for the fetus $[29,30]$. Physical activity may be reduced during pregnancy by selecting less demanding activities or decreasing the pace of activities [19].

Broad variations in energy requirements during pregnancy exist between well-nourished women in developed countries compared to women from low-income, developing societies, where the availability of nutritious foods is limited $[1,2,6,13]$. Special consideration should be given to the women with low and high Body Mass Index (BMI) as energy adaptations or responses to pregnancy may not reflect optimal nutritional conditions [4].

Underweight (BMI $\left.<18.8 \mathrm{~kg} / \mathrm{m}^{2}\right)$ Gambian women living under constraints of limited food supply and obligatory intense physical activity reduced their resting energy expenditure to allow the delivery of a viable infant who may or may not be small for gestational age, depending on the severity of the energy imbalance [5]. Normal-weight women in developing countries with unlimited food availability tend to conserve energy by reducing physical activity $[5,28]$. However, this is not always the case, since hormonal changes facilitate fat deposition and due to non-restrictive energy supply, these women tend to gain additional fat stores [5]. With regards to overweight women (BMl $\left.>25 \mathrm{~kg} / \mathrm{m}^{2}\right)$ in developed countries with free access to food, ample energy reserves are present at conception to protect fetal growth. Therefore, there is no need to accumulate fat $[5,19]$.

The possibility to offset the potential for further increases in energy storing, basal metabolic rate increases in overweight and obese women [5,31]. However, if excessive energy storage occurs, despite increases in basal metabolic rate, the excessive weight gain can be detrimental for both mother and infant $[5,17]$. Promoting methods to increase energy expenditure in overweight, pregnant women can be extremely valuable to promote energy balance and a good pregnancy outcome by reducing excessive weight gain $[17,32]$.

In South Africa, the prevalence of obesity, especially among women, has increased due to urbanization, increased wealth, increased dietary intake and decreased physical activity [33]. Furthermore, cultural factors shape South African (SA) women's eating habits, such as overeating at social gatherings where food is abundant, associating particular foods with social status, being more accepting of being overweight and relating thinness with illness and HIV/AIDS [34]. It was found SA black women living in an urban towns in South Africa to have a diverse eating pattern, which leads to the consumption of an energy-dense diet that is high in proteins and fat [35]. Another study from non-pregnant SA women found total energy expenditure to be lower in black than white women, due to the lower measured activity energy 
expenditure and smaller fat-free mass in black women [36]. Preventing excessive weight gain and treating obesity in young black women by propagating a healthy lifestyle [37] is essential during the reproductive period.

Energy requirements during pregnancy should be derived based on healthy populations with favorable outcomes [1, 4]. As stated by Löf [19], if the energy expended on physical activity is unknown, pregnant women may be encouraged to increase their energy intake above the required levels, potentially leading to an increased risk of excessive weight gain. Both sides of the energy balance equation-energy intake and expenditure-should be accounted for in relation to gestational weight gain and birth weight $[3,38]$.

Therefore, this paper aims to determine the changes that occur in energy intake and expenditure from the first to the third trimester of pregnancy in women from the Tlokwe Municipal area of South Africa. It was hypothesized that both energy intake and energy expenditure would increase significantly from the first to the third trimester of pregnancy in women from the Tlokwe Municipal area of South Africa.

Benefits of the study include objective measurements of energy expenditure in combination with energy intake, which would lead to a more accurate determination of energy balance. If energy imbalances occur, corrective measurements can be taken by means of nutritional and physical activity guidelines during pregnancy.

\section{Methods}

\section{Research design}

A longitudinal observational cohort study design was followed within the longitudinal Habitual Activity Patterns during PregnancY (HAPPY)-study. The study aimed to determine the longitudinal changes in energy intake and energy expenditure from the first to the third trimester of pregnancy. Women were measured in their first (9-14 weeks), second (20-22 weeks) and third trimesters (28-32 weeks) of pregnancy. These measurements were purposefully aligned to the recommended sonar measurements that are routinely performed by gynecologists. The setting for the study was in the Tlokwe Municipality of the North-West Province, South Africa.

\section{Participants}

The study recruited 41 pregnant women. Participants were recruited using advertisements placed in the local press and the consulting rooms of local gynecologists and clinics in the Tlokwe Municipality of Potchefstroom, North West Province, South Africa. Based on the following criteria, participants were included in the study: healthy pregnant women from any ethnic background, over 18 years of age and in their first trimester of pregnancy (9-14 weeks of gestation). Participants were excluded from the survey if they were mentally disabled or had physical limitations. A health screen was performed about risk factors for physical activity during pregnancy and for cardiovascular disease to determine whether participants were included or excluded in the study, as indicated by the American College of Sports Medicine (39). The 
participants who indicated interest in the study were asked to give their informed consent to participate in the study by signing an informed consent form. Ethical approval, complying with the Declaration of Helsinki, was obtained from the Ethics Committee of the North-West University (NWU-00044-10-A1).

\section{Demographic and pregnancy-related information}

During the first measurement, a demographic questionnaire was used to obtain information about the participants' ethnicity and age. This questionnaire was compiled specifically for the current study. Additional questions to the questionnaire about pregnancy-related data were collected, which included the following: recall pre-pregnancy weight $(\mathrm{kg})$, weeks of pregnancy, type of pregnancy (single, twin or triplets), expected date of birth and the number of previous pregnancies.

\section{Energy intake measurements}

At every measurement point, each participant's dietary intake was measured using a semi-quantitative food frequency questionnaire, which determined the nutrient intake of the participant in every trimester [40]. The data was analyzed using the Food-Finder 4 program (Medical Research Council, Tygerberg, South Africa). Energy intake (kJ/day), as well as carbohydrate, lipid and protein intake (g/day), was calculated.

\section{Energy expenditure measurements}

Total energy expenditure was calculated as the sum of resting energy expenditure, diet-induced thermogenesis and activity energy expenditure.

\section{Resting energy expenditure}

Resting energy expenditure was determined by employing indirect calorimetry with the FitMate ${ }^{\mathrm{TM}}$ (Cosmed, Italy). The FitMate ${ }^{\mathrm{TM}}$ is a metabolic analyzer designed for the measurement of oxygen consumption and energy expenditure during rest and exercise [41]. The FitMate ${ }^{\mathrm{TM}}$ gives accurate and reproducible oxygen consumption and resting energy expenditure measurements for female adults $(r=$ $0.97, p=0.066$ ) [41]. With the FitMate analyzer, ventilation is measured by a turbine flow meter, while analyses of the fraction of oxygen in expired gases are measured through a galvanic fuel cell oxygen sensor [41]. The FitMate ${ }^{\mathrm{TM}}$ uses standard metabolic formulas to calculate oxygen consumption (measured in $\mathrm{ml} / \mathrm{min}$ ), while energy expenditure (measured in $\mathrm{kJ} /$ day) is calculated using a fixed respiratory quotient of 0.85 [41].

Participants were requested not to perform any exercises during the 24 hours preceding the resting energy expenditure measurement. They were also requested to be fasting for at least 10 hours before the last- 
mentioned measurement. The FitMate ${ }^{\mathrm{TM}}$ was calibrated before each participant was subjected to the measurement. During the test, participants were requested to remain awake for the entire testing period while they breathed through an anti-bacterial filter for 15 minutes after a 10-minute resting period. During that time, the fraction of oxygen in expired gases was quantified to determine resting energy expenditure. The first minute of the measurement was discarded as it was considered as the stabilization period for breathing. Resting energy expenditure was then divided by weight and presented in $\mathrm{kJ} / \mathrm{kg}$ body weight.

\section{Activity energy expenditure}

Activity energy expenditure was determined using an objective assessment based on combined accelerometry (movement counts) and heart rate response (ActiHeart ${ }^{\circledR}$, CamNtech Ltd., Cambridge, UK). The device is a waterproof, self-contained logging device that allows physical activity to be measured synchronously with the heart rate [42]. The ActiHeart ${ }^{\circledR}$ reports simulated heart rate within a beat per minute and above 30 beats per minute, which is comparable to heart rate monitors $[42,43]$. The device is worn on the chest and consists of two electrodes (connected by a short lead) that clip onto two standard electrocardiograph (ECG) pads. The reliability and validity of the device to measure physical activity were scientifically validated $(p=0.9)$ in healthy pregnant women in Switzerland [44].

At every measurement interval in the study, activity energy expenditure was measured for a period of seven days. The following parameters were extracted from the data: activity energy expenditure, dietinduced thermogenesis and total energy expenditure. The activity energy expenditure, diet-induced thermogenesis and total energy expenditure measurements were all expressed in $\mathrm{kJ} / \mathrm{kg} / \mathrm{day}$.

For the ActiHeart ${ }^{\circledR}$ to calculate the most accurate activity energy expenditure, resting energy expenditure was determined and an eight-minute calibration step test with a ramp protocol on a step box $(21.5 \mathrm{~cm}$ in height) was conducted. The resting energy expenditure measurement and the step test were administered at every measurement interval. This individual calibration step test develops a heart rate and a $\mathrm{VO}_{2}$ regression line specifically for pregnant women and takes into account the physiological changes that the women experience during pregnancy [44].

Before the measurements, the ECG pads were placed on the chest to form an arc across the heart. Fifteen minutes was given to determine a good signal, ensuring an accurate measurement of the heart rate for the following seven consecutive days. When a sound signal was established, the eight-minute calibration step test with the ActiHeart ${ }^{\circledR}$ for activity energy expenditure calculation was done. Participants were able to stop at any time during the step test if they experienced any discomfort or fatigue. Two minutes of quiet sitting was required after the step test to determine the participants' recovery heart rates.

As soon as the step test information was downloaded using the accompanying software, the ActiHeart ${ }^{\circledR}$ was set to "Advanced Energy Expenditure" mode. Participants wore the device for seven consecutive days. The ActiHeart ${ }^{\circledR}$ was programmed to measure energy expenditure using 30 -second epochs (counts per minute). The women were advised to take the monitor off when they were bathing or showering and 
to put it on again immediately afterward. The device was removed after seven days and the data captured was downloaded using the accompanying software (Version 2.132, Cambridge Neurotechnology Ltd., Cambridge, UK). Subjects were encouraged to wear the ActiHeart® for seven days. If the subjects did not adhere to this recommendation, the data was trimmed and only the days on which measurements were taken were included. For accurate results, participants should have worn the ActiHeart ${ }^{\circledR}$ for at least four days, of which one of the days should have been a day over a weekend [45].

\section{Diet-induced thermogenesis}

Diet-induced thermogenesis was estimated by the ActiHeart® device, which is factored in as a constant of $10 \%$ of the total energy expenditure [45].

\section{Energy balance}

In the study, energy balance was determined by applying the following equation:

Energy Balance $=$ Total Energy Intake - Total Energy Expenditure

$$
E_{B}=E_{I}-(R E E+D I T+A E E)
$$

\section{$E_{B}=$ Energy balance}

$E_{I}=$ Energy intake as measured via a semi-quantitative food frequency questionnaire (kJ/day)

$\boldsymbol{R E}=$ Resting energy expenditure as determined by the Fitmate ${ }^{T M}(\mathrm{~kJ} /$ day)

DIT $=$ Diet-induced thermogenesis as estimated by the ActiHeart ${ }^{\circledR}(\mathrm{kJ} /$ day)

AEE $=$ Activity energy expenditure as determined by the ActiHeart $\left.{ }^{(}\right)(\mathrm{kJ} /$ day $)$

\section{Gestational weight gain}

Gestational weight gain, measured by an electronic Scale (Beurer, Germany), was computed for each trimester by subtracting the measured weight of the previous trimester from the weight measured in the specific trimester. Gestational weight gain $(\mathrm{kg})$ in the first trimester was calculated by subtracting selfreported pre-pregnancy weight from the measured weight in the first trimester.

\section{Statistical analysis of data}

Statistical analyses were performed with the SPSS software package, SPSS version 25 (IBM Corp, NY). The descriptive statistics of the baseline characteristics were determined, while reporting means and standard deviations. Descriptive statistics were also performed on energy intake and energy expenditure variables. Body Mass Index (BMI) was categorized according to underweight, normal, overweight and obese classifications according to the ACSM's scale [24]. 
Changes within energy intake and expenditure throughout pregnancy were analyzed using mixed-model analysis, a Bonferroni post-hoc test and an unstructured covariance structure. The dependent variables, energy intake $(\mathrm{kJ})$ and energy expenditure $(\mathrm{kJ})$ from first to third trimester of pregnancy were included in the analysis. For it to be statistically significant, the change between energy intake and energy expenditure from pre-pregnancy to three months postpartum was determined by setting the $p$-value lower than 0.05 . For practical significance (Cohen's d), 0.2 can be considered as a 'small' effect size, 0.5 representing a 'medium' effect size and 0.8 a 'large' effect size.

\section{Results}

The demographic information of the participants is presented in Table 1. The average age of the participants was approximately $28( \pm 5)$ years. There was an equal distribution in the ethnicity of the participants between the groupings in South Africa. Gestational weight equated $3.23 \pm 3.61 \mathrm{~kg}$ in the first trimester, $5.18 \pm 5.37 \mathrm{~kg}$ in the second trimester and $4.90 \pm 3.10 \mathrm{~kg}$ in the third trimester.

\section{Table 1: Demographic and anthropometric information of pregnant women in their first trimester as well as pregnancy-related information}




\begin{tabular}{|c|c|c|c|}
\hline & $\mathbf{N}$ & Mean & SD \\
\hline Age (years) & 72 & 28 & 5 \\
\hline Pre-pregnancy weight (kg) & 72 & 63 & 13 \\
\hline $\mathrm{BMI}\left(\mathrm{kg} / \mathrm{m}^{2}\right)$ & 41 & 25.48 & 5.10 \\
\hline Total weight gain over pregnancy $(\mathrm{kg}) *$ & 12 & 13.50 & 5.59 \\
\hline \multicolumn{4}{|c|}{ Underweight / Normal / Overweight and Obese (\%)** } \\
\hline Underweight $\left(\mathrm{BMI}<18.5 \mathrm{~kg} / \mathrm{m}^{2}\right)$ & 2 & 5 & \\
\hline Normal (BMI = 18.5-24.9) & 20 & 49 & \\
\hline Overweight and Obese (BMI $\geq 25.0$ ) & 19 & 46 & \\
\hline \multicolumn{4}{|l|}{ Ethnicity (\%) } \\
\hline White & 29 & 40 & \\
\hline Black & 23 & 32 & \\
\hline Mixed race & 20 & 28 & \\
\hline \multicolumn{4}{|l|}{ Number of previous pregnancies (\%) } \\
\hline 0 & 29 & 40 & \\
\hline 1 & 29 & 40 & \\
\hline 2 & 12 & 17 & \\
\hline 3 & 2 & 3 & \\
\hline \multicolumn{4}{|l|}{ Type of pregnancy (\%) } \\
\hline Single & 46 & 98 & \\
\hline Twin & 1 & 2 & \\
\hline \multicolumn{4}{|c|}{$\begin{array}{l}\mathrm{N}=\text { sample size, } \mathrm{SD}=\text { Standard deviation, } \mathrm{kg}=\text { kilogram, } \mathrm{BMI}=\text { Body Mass Index, } \\
\mathrm{kg} / \mathrm{m}^{2}=\text { kilogram per meter squared, } \%=\text { percentage, } \\
\text { * Calculated as weight ( } 3^{\text {rd }} \text { trimester) - pre-pregnancy weight (self-reported) } \\
\text { ** Categorized according to ACSM }(2018)\end{array}$} \\
\hline
\end{tabular}

Energy intake and expenditure variables are presented in Table 2. Energy intake throughout pregnancy did not differ significantly. There was a small increase in energy intake from the first trimester $(8841 \pm 3456$ $\mathrm{kJ} /$ day) to the second trimester (9134 $\pm 3046 \mathrm{~kJ} /$ day), whereas energy intake declined in the third trimester of pregnancy $(8171 \pm 3017 \mathrm{~kJ} /$ day). Macronutrient intake is also presented in Table 2 . Carbohydrate intake was calculated as $256.4 \pm 99.9 \mathrm{~g} /$ day, $264.7 \pm 86.2 \mathrm{~g} /$ day and $244.5 \pm 137.7 \mathrm{~g} / \mathrm{day}$ in the first, second and third trimesters of pregnancy, respectively. Similar to energy intake and carbohydrate intake, lipid intake increased from the first trimester $(71.5 \pm 33.0 \mathrm{~g} /$ day $)$ to the second trimester $(77.9 \pm 34.6 \mathrm{~g} /$ day $)$ and declined in the third trimester $(67.6 \pm 24.0 \mathrm{~g} /$ day $)$. Protein intake decreased throughout pregnancy, from $81.7 \pm 44.1 \mathrm{~g} /$ day in the first trimester, $79.2 \pm 32.8 \mathrm{~g} /$ day in the second trimester and $67.7 \pm 20.8 \mathrm{~g} /$ day in the third trimester.

\section{Table 2: Energy intake, energy expenditure and gestational weight gain of pregnant women in each trimester}




\begin{tabular}{|c|c|c|c|c|c|c|c|c|}
\hline \multirow[t]{2}{*}{ Variable } & \multicolumn{2}{|c|}{$1^{\text {st }}$ trimester } & \multicolumn{2}{|c|}{$2^{\text {nd }}$ trimester } & \multicolumn{2}{|c|}{$3^{\text {rd }}$ trimester } & \multicolumn{2}{|c|}{ Mixed-model analysis } \\
\hline & Mean & SD & Mean & SD & Mean & SD & F-value & $p$ \\
\hline Energy intake (kJ/day) & 8841 & 3456 & 9134 & 3046 & 8171 & 8171 & 0.420 & 0.661 \\
\hline Carbohydrate intake (g/day) & 256.4 & 99.9 & 264.7 & 86.2 & 244.5 & 137.7 & 0.173 & 0.8452 \\
\hline Lipid intake (g/day) & 71.5 & 33.0 & 77.9 & 34.6 & 67.6 & 24.0 & 0.684 & 0.512 \\
\hline Protein intake (g/day) & 81.7 & 44.1 & 79.2 & 32.8 & 67.7 & 20.8 & 0.607 & 0.552 \\
\hline Energy expenditure (kJ/day) & 10234 & 2314 & 9523 & 2732 & 9535 & 2326 & 0.184 & 0.314 \\
\hline Resting energy expenditure (kJ/day) & 5552 & 1259 & 5502 & 1456 & 6012 & 1845 & 2.829 & 0.066 \\
\hline Activity energy expenditure (kJ/day) & 3519 & 1967 & 2941 & 1958 & 2423 & 1573 & 2.360 & 0.104 \\
\hline Diet-induced thermogenesis ( $\mathrm{kJ} /$ day) & 1059 & 234 & 1021 & 285 & 987 & 193 & 0.928 & 0.402 \\
\hline Energy balance (kJ/day) & -1377 & 4548 & 381 & 4213 & -1331 & 3732 & 1.665 & 0.205 \\
\hline Gestational weight gain (kg) & 3.23 & 3.61 & 5.18 & 5.37 & 4.90 & 3.10 & & \\
\hline
\end{tabular}

$\mathrm{SD}=$ Standard deviation, $\mathrm{F}=\mathrm{F}$ statistic, $p=$ statistical significance, $\mathrm{kJ} /$ day $=$ kilojoule per day, $\mathrm{g} /$ day $=\mathrm{gram} \mathrm{per}$ day, $\mathrm{kg}=$ kilogram.

Results from the mixed-model analysis are presented in Table 2. No statistically significant changes were observed in any of the variables. However, a medium practical significant difference (effect size of Cohen's $d$ ) was observed in the change of resting energy expenditure from the first to the third trimester ( $d$ $=0.44)$ and the second to the third trimester $(d=0.45)$. A medium practical significant (effect size of Cohen's d) difference was observed in the change of activity energy expenditure from the first to the third trimesters $(d=0.47)$.

Changes in energy expenditure according to BMI classifications per trimester of pregnancy are presented as a graph in Figure 1. It was found that overweight women's total energy expenditure exceeded that of normal-weight women in all three trimesters. Resting energy expenditure increased from the first trimester $(6116 \mathrm{~kJ} /$ day) to the third trimester (7669 kJ/day) in overweight women, while normal-weight women's resting energy expenditure decreased slightly from the first trimester $(5019 \mathrm{~kJ} /$ day $)$ to the second trimester (4991 kJ/day), while increasing in the third trimester $(6779 \mathrm{~kJ} /$ day). Activity energy expenditure decreased considerably in overweight women from the first trimester $(3929 \mathrm{~kJ} /$ day) to the third trimester (2056 kJ/day), while normal-weight women's activity energy expenditure increased from the first trimester $(2965 \mathrm{~kJ} /$ day) to the second trimester $(3362 \mathrm{~kJ} /$ day). Thereafter, it decreased to the third trimester (2056 $\mathrm{kJ} /$ day).

\section{Figure 1: Change in energy expenditure from the first to the third trimester of pregnancy categorized in normal and overweight pregnant women}

The energy balance during the first $(-1375 \pm 4548 \mathrm{~kJ} /$ day $)$ and the third trimester $(-1331 \pm 3734 \mathrm{~kJ} /$ day $)$ were negative, while a minor positive energy balance was observed in the second trimester $(380 \pm 4212$ $\mathrm{kJ} / \mathrm{day})$. 


\section{Discussion}

The aim was to determine the longitudinal changes that occur in energy intake and expenditure throughout a pregnancy. As a characteristic of pregnant women, high variability is seen in energy intake and energy expenditure, and thus, in pregnant women's energy costs [4]. As such, recommendations in terms of energy intake and habitual physical activity patterns should be population-specific and determined by socio-economic and cultural factors that are specific to the population [4]. The subjects in the current study were representative of the South African population in terms of ethnicity.

\section{Energy intake}

In this study, no significant changes were observed relating to energy intake throughout pregnancy. Similarly, other studies reported non-significant increases in energy intake $[1,3,46]$. As per this study, the participants presented with a negative energy balance in the first and third trimesters of their pregnancies, which corresponds with previous studies $[3,46]$. In spite of the negative energy balance, an increase in weight was still observed. The findings are similar to that reported by a systematic review that found that both women from developed and developing countries appear to only consume a quarter of the theoretical requirement for additional energy, despite uniquely rapid weight gain [3].

\section{Macronutrient intake}

No statistically significant changes in macronutrient intake per trimester of pregnancy were observed in this study. However, in a systematic review of developed countries, it was found that macronutrient intake to increase during each trimester of pregnancy [47]. In contrast, carbohydrate intake increased from the first to the second trimester even though a decrease was found from the second to the third trimester of pregnancy in this cohort. Similar to carbohydrate intake, this cohort's lipid intake increased from the first to the second trimester and decreased from the second to the third trimester of pregnancy. Protein intake decreased from the first to the third trimester in this cohort. The difference in macronutrient intake could be attributed to the differences in developed and developing countries, whereas the availability of additional food outside the normal intake is hampered by poverty.

\section{Resting energy expenditure}

Nonetheless, dietary insufficiencies in undernourished women might be diminished by energy-sparing strategies to protect fetal growth [31]. One of the energy-sparing adaptations that occur is a decrease in resting energy expenditure, which is also known as metabolic "flexibility" in the resting energy expenditure during pregnancy [31]. In this cohort, resting energy expenditure declined from the first to the second trimester, yet increased in the third trimester. It was also found that the increase in resting energy expenditure in the third trimester is significantly correlated with higher body mass during pregnancy [25]. Although no statistically significant changes were observed in the change of resting energy expenditure 
throughout each trimester of pregnancy, a medium practically significant difference was observed between the first and third trimester, as well as the second and third trimester. Again, this medium practical significant difference emphasizes the contribution of resting energy expenditure to total energy expenditure, whereas the contribution of activity energy expenditure tends to be relatively small and constant from one person to another [25].

\section{Activity energy expenditure}

Another energy-sparing adaptation is a decrease in energy expenditure through physical activity $[23,25]$. Despite non-statistically significant differences between activity energy expenditure throughout pregnancy, a practical significant decline of activity energy expenditure was observed from the first to the third trimester. A non-significant decrease in activity energy expenditure during pregnancy was also found, which, in accordance with other studies, proves that physical activity declines during pregnancy $[25,26,48-53]$. A decline in activity energy expenditure can be accounted for due to women shifting toward less intense and more comfortable modes of activity, probably to avoid the risk of maternal and fetal injuries as well as to accommodate an increase in body weight.

\section{Energy expenditure of normal versus overweight/obese women}

Differences relating to energy expenditure variables in normal versus overweight or obese women are varying [4]. In agreement with [4] this study's overweight or obese cohort, women's total energy expenditure was higher than that of the normal-weight women. The increase in total energy expenditure can primarily be ascribed to the higher increase in resting energy expenditure in the overweight or obese women compared to the normal-weight women $[4,25,54]$. Furthermore, activity energy expenditure decreased more noticeably in overweight or obese women from the first to the third trimester, when compared to normal-weight women. Finally, it was found that sedentary SA women tended to be above the recommended weight-gain ranges, however, their study found physical activity to increase as the pregnancy progressed [55].

\section{Strengths and limitations of the study}

The strengths of the study include the measurement of both dietary energy and macronutrient intake in conjunction with energy expenditure data which has been captured by an objectively measured heart rate accelerometer $\left(\right.$ ActiHeart $\left.^{\circledR}\right)$. When examining energy balance, data should include both energy intake and energy expenditure data $[3,38]$.

The findings of this study should, however, be interpreted with some limitations in mind, such as the reliance on self-reported data with the use of the semi-quantitative Food Frequency Questionnaire. Energy intake underreporting amongst pregnant women should be acknowledged in dietary research [56].

Furthermore, due to the convenience sampling method applied, women who were more active might have 
been more interested to participate in the study. Activity energy expenditure data was captured during a five-day period, which could have led to changes in the participants' normal behavior during the study period. Another limitation was the use of estimates of body composition. Lastly, the compliance to the longitudinal design in the study was weak, especially pertaining to women measured from low socioeconomic areas, which limited the sample size of the study.

\section{Conclusion}

In conclusion, no statistically significant changes were observed in energy intake and expenditure during pregnancy in women from the Tlokwe Municipality area. The additional energy expenditure in the third trimester, mostly attributed to resting energy expenditure, was partly compensated for by the decrease in activity energy expenditure. Energy-sparing adaptations may be more important in balancing the energy budget of pregnant women in populations where restricted food intakes and demands of physical activity are higher. It was found that overweight and obese pregnant women had a higher energy expenditure compared to normal-weight pregnant women, primarily due to their higher resting energy expenditure. However, their activity energy expenditure decreased more pronouncedly when compared to normalweight women. Variability in responses to energy requirements of pregnancy is essential in providing a healthy pregnancy outcome for both mother and infant. Recommendations for future research include the study of how variations in energy balance influence gestational weight gain and fetal growth.

\section{Abbreviations}

ACSM = American College of Sports Medicine

$\mathrm{AEE}=$ Active Energy Expenditure

$\mathrm{BMI}=$ Body Mass Index

$\mathrm{cm}=$ centimeter

DIT = Diet-Induced Thermogenesis

$E_{B}=$ Energy balance

$E_{1}=$ Energy intake

g/day = gram per day

HAPPY = Habitual Activity Patterns during PregnancY

$\mathrm{kg}=$ kilogram

$\mathrm{kg} / \mathrm{m}^{2}=$ kilogram per square meter 
$\mathrm{kJ} /$ day $=$ kilojoule per day

$\mathrm{kJ} / \mathrm{kg} /$ day = kilojoule per kilogram per day

$\mathrm{N}$ = sample size

$p=$ significance level

$r=$ correlation coefficient

$\mathrm{REE}=$ Resting Energy Expenditure

$S A=$ South Africa

SD = Standard Deviation

$\mathrm{VO}_{2}=$ oxygen consumption

\section{Declarations}

\section{Ethics approval and consent to participate}

The participants who indicated interest in the study were asked to give their informed consent to participate in the study by signing an informed consent form. Ethical approval, complying with the Declaration of Helsinki, was obtained from the Ethics Committee of the North-West University (NWU00044-10-A1).

\section{Consent for publication}

Not applicable.

\section{Availability of data and materials}

The datasets used and/or analysed during the current study are available from the corresponding author on reasonable request.

\section{Competing interests}

The authors declare not competing interests.

\section{Funding}


The research was funded by the National Research Foundation South African-Swiss Joint Programme, award number UID 78606 and the South African Sugar Association, project no 224. Any opinion, findings and conclusions or recommendations expressed in this material are those of the authors, and therefore the NRF does not accept liability in regard to it.

\section{Authors' contributions}

SJ and YS conceived and designed the study. AF is a PhD candidate and together with SJ collected the data and performed the analysis. AF drafted the manuscript. SJ and YS critically reviewed the manuscript. All authors read and approved the final manuscript.

\section{Acknowledgements}

The authors would like to acknowledge the North-West Department of Health, the nurses at the relevant clinics, participating gynecologists' and participants in this study for their time and support.

\section{References}

1. Butte NF, King JC. Energy requirements during pregnancy and lactation. Public Health Nutr. 2005;8(7A):1010-27.

2. FAO (Food and Agriculture Organization of the United Nations). Human energy requirements. Food Nutr Bull. 2001;26(1):1-96.

3. Jebeile H, Mijatovic J, Chun J, Louie Y, Prvan T, Brand-Miller JC. A systematic review and metaanalysis of energy intake and weight gain in pregnancy. Am J Obstet Gynecol [Internet]. 2016;214(4):465-83. Available from: http://dx.doi.org/10.1016/j.ajog.2015.12.049

4. Butte NF, Wong WW, Treuth MS, Ellis KJ, Smith EOB. Energy requirements during pregnancy based on total energy expenditure and energy deposition. Am J Clin Nutr [Internet]. 2004;79(1):1078-87. Available from: http://ajcn.nutrition.org/content/79/6/1078.full.pdf+html

5. King J, King C, Butte F. Energy metabolism during pregnancy: influence of maternal energy status energy during pregnancy: Am J Clin Nutr. 1994;59(2 Suppl):439S-445S.

6. Kopp-Hoolihan LE, van Loan MD, Wong WW, King JC. Longitudinal assessment of energy balance in well-nourished, pregnant women. Am J Clin Nutr [Internet]. 1999;69(4):697-704. Available from: http://www.ncbi.nlm.nih.gov/pubmed/10197571

7. Kruger HS. Maternal anthropometry and pregnancy outcomes: a proposal for the monitoring of pregnancy weight gain in outpatient clinics in South Africa. Curationis. 2005;28(4):40-9.

8. Lof M, Forsum E. Activity pattern and energy expenditure due to physical activity before and during pregnancy in healthy Swedish women. Br J Nutr [Internet]. 2006;95(2):296. Available from: http://www.journals.cambridge.org/abstract_S0007114506000390 
9. Abeysekera M V., Morris JA, Davis GK, O'Sullivan AJ. Alterations in energy homeostasis to favour adipose tissue gain: A longitudinal study in healthy pregnant women. Aust New Zeal J Obstet Gynaecol. 2016;56(1):42-8.

10. Ladyman SR, Augustine RA, Grattan DR. Hormone Interactions Regulating Energy Balance During Pregnancy Neuroendocrinology. J Neuroendocrinol. 2010;22(6):805-17.

11. Kazemian E, Sotoudeh G, Dorosty-motlagh AR, Eshraghian MR, Bagheri M. Maternal Obesity and Energy Intake as Risk Factors of Pregnancy-induced Hypertension among Iranian Women. J Heal Popul Nutr. 2014;32(3):486-93.

12. Stotland NE, Hopkins LM, Caughey AB. Gestational weight gain, macrosomia, and risk of cesarean birth in nondiabetic nulliparas. Obstet Gynecol. 2004;104(4):671-7.

13. IOM C to RIPWI of MNRC. Weight Gain During Pregnancy: Reexamining the Guidelines; Institute of Medicine [Internet]. Rasmussen KM, Yaktine AL, editors. Washington, DC: The National Academies Press; 2009. 869 p. Available from: http://www.ncbi.nlm.nih.gov/pubmed/20669500

14. Rush D. Maternal nutrition and perinatal survival. J Heal Popul Nutr [Internet]. 2001;19(3):S217-64. Available from: http://www.ncbi.nlm.nih.gov/pubmed/20974412

15. Ådén E, Johansson I, Håglin L. Energy and nutrients in self-reported diet before and at week 18-22 of pregnancy. Scand J Food Nutr. 2007;51(2):67-73.

16. Brion MJA, Ness AR, Rogers I, Emmett P, Cribb V, Smith GD, et al. Maternal macronutrient and energy intakes in pregnancy and offspring intake at $10 \mathrm{y}$ : Exploring parental comparisons and prenatal effects. Am J Clin Nutr. 2010;91(3):748-56.

17. Stuebe AM, Oken E, Gillman MW. Associations of diet and physical activity during pregnancy with risk for excessive gestational weight gain. Am J Obstet Gynecol [Internet]. 2009;201(1):58.e1-58.e8. Available from: http://dx.doi.org/10.1016/j.ajog.2009.02.025

18. New Zealand Ministry of Health. Food and nutrition guidelines for healthy adults: A background paper. 2006. 2-212 p.

19. Löf M. Physical activity pattern and activity energy expenditure in healthy pregnant and nonpregnant Swedish women. Eur J Clin Nutr. 2011;65129(10):1295-301.

20. Abeysekera M V, Morris JA, $O$ 'sullivan AJ. Techniques to measure free-living energy expenditure during pregnancy-A guide for clinicians and researchers. Obstet Med. 2014;7(2):60-5.

21. Highman TJ, Friedman JE, Huston LP, Wong WW, Catalano PM. Longitudinal changes in maternal serum leptin concentrations, body composition, and resting metabolic rate in pregnancy. Am J Obstet Gynecol. 1998;178(5):1010-5.

22. Prentice AM, Goldberg GR, Davies HL, Murgatroyd PR, Scott W. Energy-sparing adaptations in human pregnancy assessed by whole-body calorimetry. Br J Nutr [Internet]. 1989;62(1):5-22. Available from: http://ovidsp.ovid.com/ovidweb.cgi?T = JS\&PAGE = reference\&D $=$ emed2\&NEWS $=$ N\&AN $=$ 1989226429

23. Clarke PE, Rousham EK, Gross H, Halligan AWF, Bosio P. Activity patterns and time allocation during pregnancy: a longitudinal study of British women. Ann Hum Biol. 2005;32(3):247-58. 
24. ACSM. ACSM's Guidelines for Exercise Testing and Prescription. 10th editi. Riebe D, Ehrman JK, Liguori G, Magal M, editors. Baltimore, MD: Wolters Kluwer; 2018. 472 p.

25. Melzer K, Schutz Y, Boulvain M, Kayser B. Pregnancy-related changes in activity energy expenditure and resting metabolic rate in Switzerland. Eur J Clin Nutr [Internet]. 2009;63(10):1185-91. Available from: http://dx.doi.org/10.1038/ejcn.2009.49

26. Abbasi $M$, Akker $O$ Van Den. A systematic review of changes in women ' s physical activity before and during pregnancy and the postnatal period. J Reprod Infant Psychol. 2015;33(4):325-58.

27. Merkx A, Ausems M, Researcher S. Factors affecting perceived change in physical activity in pregnancy. Midwifery [Internet]. 2017;51:16-23. Available from: http://dx.doi.org/10.1016/j.midw.2017.05.007

28. Van Oort AF. The relationship between habitual physical activity patterns of pregnant women and foetal growth parameters: a longitudinal observational study. North-West University; 2014.

29. Coll CVN, Domingues MR, Gonc H, Bertoldi AD. Perceived barriers to leisure-time physical activity during pregnancy: A literature review of quantitative and qualitative evidence. J Sci Med Sport. 2017;20(1):17-25.

30. Melzer K, Schutz Y, Soehnchen N, Othenin-Girard V, Martinez de Tejada B, Irion O, et al. Effects of recommended levels of physical activity on pregnancy outcomes. Am J Obstet Gynecol [Internet]. 2010;202(3):266.e1-266.e6. Available from: http://dx.doi.org/10.1016/j.ajog.2009.10.876

31. Byrne NM, Groves AM, McIntyre HD, Callaway LK. Changes in resting and walking energy expenditure and walking speed during pregnancy in obese women. Am J Clin Nutr. 2011;94(3):819-30.

32. Mottola MF. Physical activity and maternal obesity: Cardiovascular adaptations, exercise recommendations, and pregnancy outcomes. Nutr Rev. 2013;71(SUPPL1):31-6.

33. Sartorius B, Veerman LJ, Manyema M, Chola L, Hofman K. Determinants of obesity and associated population attributability, South Africa: Empirical evidence from a national panel survey, 2008-2012. PLoS One. 2015;10(6):1-20.

34. Kruger HS, Puoane T, Senekal M, van der Merwe MT. Obesity in South Africa: challenges for government and health professionals. Public Health Nutr. 2005;8(5):491-500.

35. Hattingh Z, Walsh CM, Bester CJ, Oguntibeju OO. Evaluation of energy and macronutrient intake of black women in Bloemfontein: A cross-sectional study. African J Biotechnol [Internet]. 2008;7(22):4019-24. Available from: http://www.scopus.com/inward/record.url?eid = 2-s2.057149120334\&partnerlD = 40\&md5 = 3c777afc733bc2aad5093f5d22345e11

36. Dugas LR, Cohen R, Carstens MT, Schoffelen PFM, Luke A, Durazo-Arvizu R a, et al. Total daily energy expenditure in black and white, lean and obese South African women. Eur J Clin Nutr [Internet]. 2009;63(5):667-73. Available from: http://www.ncbi.nlm.nih.gov/pubmed/18270522

37. Kruger HS, Venter CS, Vorster HH. Obesity in African women in the North West Province, South Africa is associated with an increased risk of non-communicable diseases: the THUSA study. $\mathrm{Br} \mathrm{J}$ Nutr [Internet]. 2001;86(6):733-40. Available from: http://www.journals.cambridge.org/abstract_S000711450100246X 
38. Ruifrok A, Althuizen E, Oostdam N, van Mechelen W, Mol BW, de Groot CJM, et al. The relationship of objectively measured physical activity and sedentary behaviour with gestational weight gain and birth weight. J Pregnancy. 2014;2014:2090-727.

39. ACSM. ACSM's Guidelines for Exercise Testing and Prescription. 9th ed. Pescatello LS, editor. Baltimore, MD: Lippincott Williams and WIlkins; 2014. 456 p.

40. Maclntyre U, Venter C, Vorster H, Steyn H. A combination of statistical methods for the analysis of the relative validation data of the quantitative food frequency questionnaire used in the THUSA study. Public Health Nutr [Internet]. 2001;4(01):45-51. Available from: http://www.journals.cambridge.org/abstract_S1368980001000076

41. Nieman DC, Austin MD, Benezra L, Pearce S, Mclnnis T, Unick J, et al. Validation of Cosmed's FitMate in measuring oxygen consumption and estimating resting metabolic rate. Res Sports Med. 2006;14(2):89-96.

42. Brage S, Brage N, Franks PW, Ekelund U, Wareham NJ. Reliability and validity of the combined heart rate and movement sensor Actiheart. Eur J Clin Nutr. 2005;59(4):561-70.

43. Boudet G, Chamoux A. Heart rate monitors and abnormal heart rhythm detection. Arch Physiol Biochem [Internet]. 2000;108(4):371-9. Available from: http://www.scopus.com/inward/record.url? eid $=2$-s2.0-0034488689\&partnerlD $=$ tZOtx3y1

44. Melzer K, Lazzeri M, Armand S, Boulvain M, Schutz Y, Kayser B. Validation of the Actiheart for estimating physical activity related energy expenditure in pregnancy. Eur Soc Clin Nutr Metab J [Internet]. 2012;7(1):e5-10. Available from: http://dx.doi.org/10.1016/j.eclnm.2011.12.008

45. CamNtech. The Actiheart User Manual. Heal San Fr. 2010;35:1-95.

46. Bell R, Robson P. Lack of a significant relationship between energy intake in pregnancy and gestational weight gain underlines the need for further evaluations of energy metabolism during this time. Evid Based Med. 2016;21(5):192.

47. Blumfield ML, Hure AJ, MacDonald-Wicks L, Smith R, Collins CE. Systematic review and metaanalysis of energy and macronutrient intakes during pregnancy in developed countries. Nutr Rev. 2012;70(6):322-36.

48. Amezcua-Prieto C, Olmedo-Requena R, Jímenez-Mejías E, Hurtado-Sánchez F, Mozas-Moreno J, Lardelli-Claret $\mathrm{P}$, et al. Changes in leisure time physical activity during pregnancy compared to the prior year. Matern Child Health J. 2013;17(4):632-8.

49. Chasan-Taber L, Freedson PS, Roberts DE, Schmidt MD, Fragala MS. Energy expenditure of selected household activities during pregnancy. Res Q Exerc Sport [Internet]. 2007;78(2):133-7. Available from: http://www.ncbi.nlm.nih.gov/pubmed/17479581

50. Derbyshire BE, Davies GJ, Costareiii V, Dettmar PW. Habitual pattems of physical activity during pregnancy and postnataily. Matern Heal. 2007;16(1):20-5.

51. Leppanen M, Aittasalo M, Raianen J, Kinnunen TI, Kugala UM, Luoto R. Physical Activity During Pregnancy: Predictors of Change, Perceived Support and Barriers Among Women at Increased Risk of Gestational Diabetes. Matern Child Health J. 2014;18(9):2158-66. 
52. Most J, Gilmore LA, Altazan AD, St. Amant M, Beyl RA, Ravussin E, et al. Propensity for adverse pregnancy outcomes in African-American women may be explained by low energy expenditure in early pregnancy. Am J Clin Nutr [Internet]. 2018;107(May):1-8. Available from: http://www.ncbi.nlm.nih.gov/pubmed/29767680\%0Ahttps://academic.oup.com/ajcn/advancearticle/doi/10.1093/ajcn/nqy053/4996036

53. Poudevigne S, Connor PJO. A Review of Physical Activity Patterns in Pregnant Women and Their Relationship to Psychological Health. Sport Med. 2006;36(1):19-38.

54. Löf M, Hilakivi-Clarke L, Sandin S, Weiderpass E. Effects of pre-pregnancy physical activity and maternal BMI on gestational weight gain and birth weight. Acta Obstet Gynecol Scand. 2008;87(5):524-30.

55. Brunette EL, Kotze J, Wood PS, Du Toit PJ, Grant CC. An epidemiological study of physical activity patterns and weight gain in physically active and sedentary pregnant women in Tshwane, South Africa. African J Phys Heal Educ Recreat Danc. 2012;132-43.

56. McGowan CA, McAuliffe FM. Maternal nutrient intakes and levels of energy underreporting during early pregnancy. Eur J Clin Nutr [Internet]. 2012;66(8):906-13. Available from: http://dx.doi.org/10.1038/ejcn.2012.15.

\section{Figures}

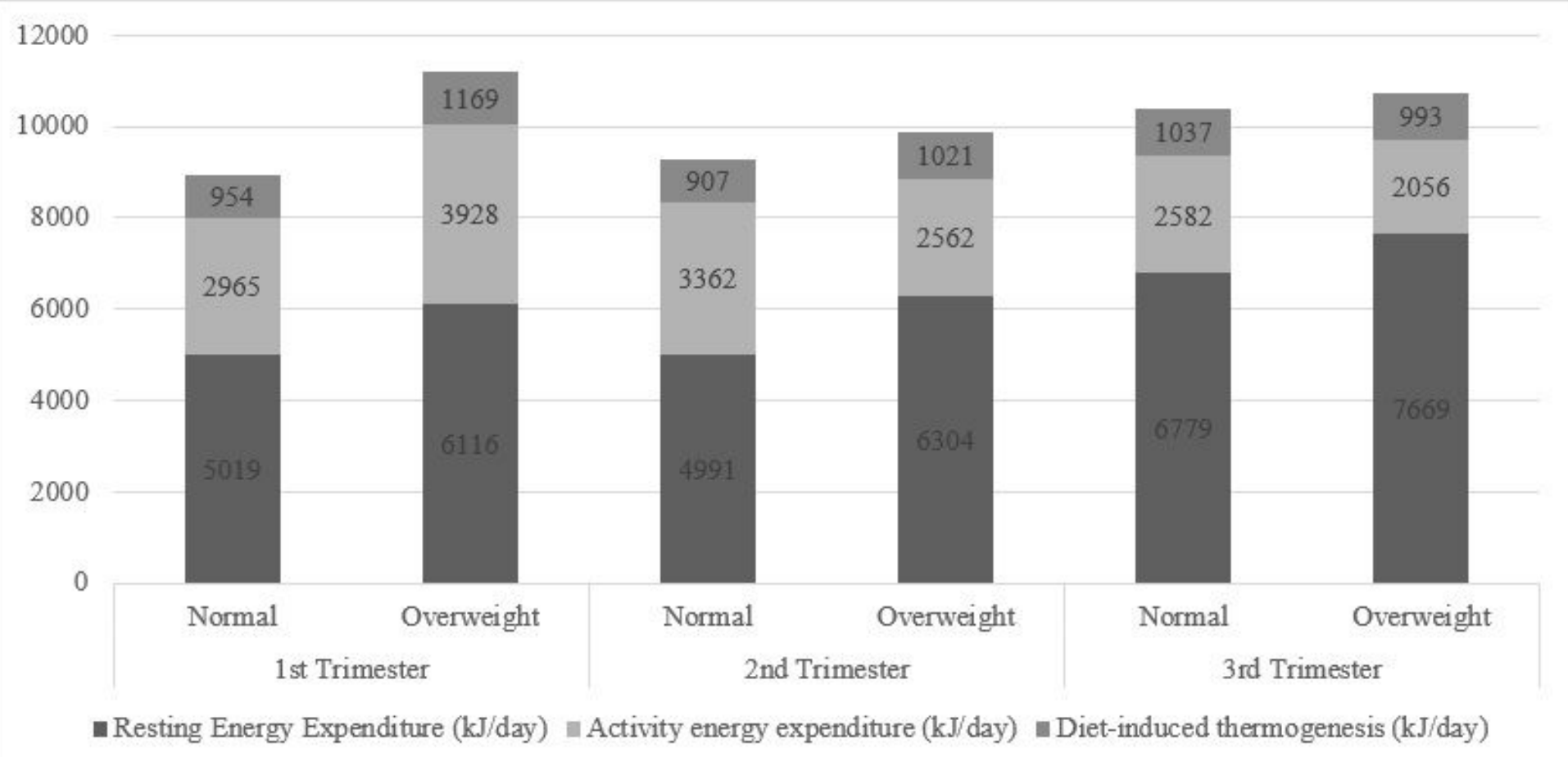

\section{Figure 1}

Change in energy expenditure from the first to the third trimester of pregnancy categorized in normal and overweight pregnant women 